\title{
Bipolar Spectrum: A Review of the Concept and a Vision for the Future
}

\author{
S. Nassir Ghaemi ${ }^{\bowtie}$ \\ Department of Psychiatry, Tufts Medical Center, Tufts University School of Medicine, Boston, MA, USA
}

This paper reviews the bipolar spectrum concept historically and empirically. It describes how the concept derives from Kraepelin, but was lost with DSM-III, which divided the broad manic-depressive illness concept, based on recurrent mood episodes of either polarity, to the bipolar versus unipolar dichotomy, based on allowing non-recurrent mood episodes of only one polarity. This approach followed the views of Karl Leonhard and other critics of Kraepelin. Thus post DSM-III American psychiatry is not neo-Kraepelinian, as many claim, but neo-Leonhardian. The bipolar spectrum approach, as advocated by Akiskal and Koukopoulos first, harkens back to the original broad Kraepelinian view of manic-depressive illness. The evidence for and against this approach is discussed, and common misconceptions, including mistaken claims that borderline personality is similar, are revealed and critiqued.

Psychiatry Investig 2013;10:218-224

Key Words Bipolar spectrum, Leonhard, Kraepelin, DSM-5, Mixed, Koukopoulos, Akiskal.

\section{BIPOLAR DISORDER $\neq$ MANIC- DEPRESSIVE ILLNESS}

The concept of a bipolar spectrum presupposes that the concept of bipolar illness is valid. The best introduction to the concept of a bipolar spectrum may be to go a step back before the bipolar concept itself, back to the earlier concept of manicdepressive insanity (MDI), usually associated with psychotic features. Introduced by Kraepelin, ${ }^{1}$ and slightly rephrased as manic-depressive illness (to include the majority of subjects without psychotic features), the MDI concept was divided officially in 1980 in the DSM-III to bipolar disorder and major depressive disorder (MDD). ${ }^{2}$ This division in turn is a variation on the original division made in the 1950s by Karl Leonhard of MDI into bipolar and unipolar recurrent psychoses, ${ }^{3}$ which, if broadened to include non-psychotic mood presentations, was rephrased in the 1960s and 1970s by American researchers (headed at the Washington University of St. Louis) as bipolar illness and unipolar depressive illness. ${ }^{4}$ This Amer-

Received: June 4, 2013 Revised: June 13, 2013

Accepted: July 13, 2013 Available online: September 16, 2013

$\triangle$ Correspondence: S. Nassir Ghaemi

Department of Psychiatry, Tufts Medical Center, 800 Washington St., Boston, MA 02111, USA

Tel: +1-617-636-5735, Fax: +1-617-636-7795

E-mail: nghaemi@tuftsmedicalcenter.org

(a) This is an Open Access article distributed under the terms of the Creative Commons Attribution Non-Commercial License (http://creativecommons.org/licenses/by$\mathrm{nc} / 3.0$ ) which permits unrestricted non-commercial use, distribution, and reproduction in any medium, provided the original work is properly cited. ican revision of Leonhard's idea was the basis for the Research Diagnostic Criteria (RDC) of the 1970s, ${ }^{5}$ which became transformed into DSM-III. ${ }^{6}$ In that last transition, from the RDC to DSM-III, the American Psychiatric Association became involved, and decisions were no longer based on research considerations primarily, but on the political preferences of the profession. ${ }^{7}$ Since most American psychiatrists were psychoanalytic, they tended to use the DSM-II diagnosis of "neurotic depression" frequently. Yet that term was excluded from the Washington University unipolar depression concept; unipolar depression consisted of severe recurrent depressive episodes. Neurotic depression was not severe (it was mild to moderate), not recurrent (it was chronic), not depressive (anxious symptoms were predominant), and not episodic (it was constant). ${ }^{8}$ Yet to pass DSM-III, the RDC criteria were altered to include all those features - being non-recurrent, chronic, and anxious - as also part of the unipolar depressive syndrome; ${ }^{7}$ this hybrid condition was renamed "major depressive disorder". The word "disorder" was tagged onto every DSM-III diagnosis to avoid making any etiological judgments; ${ }^{9}$ thus the term "illness", which implied a medical disease, was dropped, producing bipolar "disorder" and MDD.

One can see, after all these distortions, that the bipolar disorder concept is very different from manic-depressive illness. Also, one sees that MDD was broadened to include many types of depressive symptom presentations that were not seen as part of the disease of recurrent depression. In the classic 
studies on unipolar depression that led to DSM-III, the diagnosis was made only if there were three or more depressive episodes: ${ }^{10}$ recurrence was seen as essential to the disease of unipolar depression, which was seen as an "endogenous"3 (i.e., biologically-based) disease (even limited by Leonhard only to those with concurrent psychotic features).

In sum, the broad MDI concept as a medical disease was replaced by a rump concept of bipolar "disorder", and a large concept of depressive symptom-complexes (MDD).

The very narrow bipolar disorder concept differed from the old MDI concept considerably. Not only is it much narrower, but its core feature is different. For bipolar disorder, the condition is defined by polarity: presence or absence of a manic episode. ${ }^{3}$ For MDI, the condition is defined by episodicity: recurrent mood episodes define the illness, irrespective of polarity. ${ }^{1}$ Ten depressive episodes mean MDI. Ten manic episodes mean MDI. The fact that the episodes are depressive or manic is irrelevant. The number "ten" is relevant: recurrence defines the illness. ${ }^{2}$

MDI means recurrent manic OR depressive episodes. Bipolar disorder means recurrent manic AND depressive episodes. These are quite different concepts.

Put otherwise, MDI is basically bipolar disorder plus much of what we call MDD. MDI is much broader than bipolar disorder.

Often it is said that DSM-III was neo-Kraepelinian. ${ }^{11}$ It was not: for mood illnesses, it was neo-Leonhardian. ${ }^{12}$ By accepting the bipolar concept, DSM-III turned away from Kraepelin and toward Leonhard. This process has now been taken for granted with DSM-IV and now DSM-5. Psychiatry has moved away from the Kraepelinian MDI concept to such an extent that many assume that the bipolar/MDD dichotomy is obviously true.

The bipolar spectrum concept is a way of trying to go back to the Kraepelinian MDI concept, or at least to reopen the scientific discussion such that we can revisit whether it was correct to make the decision in 1980 to divide MDI into a small bipolar and large MDD concept.

\section{VALIDATORS OF DIAGNOSIS}

DSM-III divided MDI into bipolar disorder and MDD based on the accepted validators of psychiatric diagnosis, which were introduced in 1970 by the Washington University rese$\operatorname{archers}^{13}$ as five-fold: symptoms, family history, course, treatment response, and biological markers. It was claimed that bipolar disorder and MDD differed in all forms:

1. Symptoms: in both conditions, depression are present, but in only one condition is mania present. ${ }^{3}$

2. Family history: early genetic studies indicated that if ma- nia is present in a patient, it is also present in family members; but if only depression is present in a patient, mania is not present in family members. ${ }^{10,14}$

3. Course: recurrent depression was seen to have fewer and longer episodes than recurrent mania plus depression, where episodes were shorter and more frequent. Age of onset was later in recurrent depression (around age 30) and earlier in recurrent mania plus depression (around age 20)..$^{10,14}$

4. Treatment response: recurrent depression responded to tricyclic antidepressants; recurrent mania plus depression responded to lithium. ${ }^{7}$

5. Biological markers: recurrent depression was seen as involving abnormalities in norepinephrine and possibly serotonin function; recurrent mania was seen as involving abnormalities with dopamine function. ${ }^{15}$

Two classic studies, both published in the late 1960s in Europe were seen as central to confirming Leonhard's work. One large study was headed by Carlo Perris ${ }^{10}$ and a different one by Jules Angst. ${ }^{14}$ As Dr Angst frequently says, when he presented his results to his mentors, he was told that he couldn't be correct, since his results contradicted Kraepelin. Angst's work was based on his Zurich cohort, a prospective study since the late 1950s. About ten year prospective data were used by him to support the Leonhardian nosology.

\section{AFTER DSM-III}

For about two decades, the neo-Leonhardian consensus of DSM-III held. The only objections came from a few experienced clinical researchers: in the US, Hagop Akiskal, ${ }^{16}$ and in Europe, Athanasios Koukopoulos. ${ }^{17}$ Akiskal began studies in the 1970s in the first specialized mood clinic in the US, and he identified many patients who seemed to fall in between the bipolar and unipolar categories of the Washington University school. ${ }^{16}$ Yet Akiskal was part of the DSM-III process and accepted it. He thus proposed maintaining the bipolar/unipolar distinction, but broadening the bipolar category to include a "bipolar spectrum." ${ }^{16}$ In this spectrum, he included atypical depressive presentations and mood temperaments. In Rome, Koukopoulos found that he could not confirm some of the claims made in favor of the unipolar/bipolar dichotomy. In particular, he cast doubt on the treatment response criterion: many unipolar patients did not respond to antidepressants; they seemed to have other features of bipolarity, such as a highly recurrent course and early age of onset. ${ }^{17}$ Even the symptom distinction was debatable: Koukopoulos found that many depressed patients had manic symptoms, and many manic patients had depressive symptoms. In other words, mixed states were much more frequent than pure mania or pure depression, ${ }^{18}$ and thus the attempt to distinguish the two was difficult, 
and perhaps unnecessary. Both Akiskal and Koukopoulos returned to Kraepelin's work and found confirmation of their findings in the observations of Kraepelin.

An important third critic was Frederick Goodwin, director of the NIMH in the US in the late 1980s and early 1990s, when he published his classic textbook, Manic-Depressive Illness. ${ }^{2}$ Goodwin, with his coauthor Kay Jamison, reviewed the scientific literature as of 1990, and found evidence contradicting the 1960s and 70s literature that had led to the DSM-III neo-Leonhardian dichotomy. The genetic literature could be interpreted as supporting Kraepelin or Leonhard: mania did seem to run in families, but there was as much depression (or more) in families of manic probands as in families of depressive probands. ${ }^{19}$ In other words, depression did not run in families separate from mania. Further, Goodwin noted that lithium was effective in depression alone, not just bipolar disorder. ${ }^{20}$ As biological research grew in the 1990s and 2000s, it also became clear that neurotransmitter theories about catecholamines had been very simplistic in the 1970 s. $^{21}$ Second messengers and long-term neuroplastic changes in the brain were seen in mood illnesses, ${ }^{22}$ and there were often similarities between unipolar and bipolar disorder definitions in those biological mechanisms. ${ }^{23}$

In the 1990s and 2000s, the new class of atypical neuroleptics was developed which showed clear efficacy in acute mania, but also, in many cases, efficacy for depressive episodes, not limited to bipolar disorder but even in MDD with some agents. ${ }^{24}$ Some anticonvulsants, like lamotrigine, were much more effective in preventing depression rather than mania, ${ }^{25}$ and the presumed strong efficacy of antidepressants in MDD was thrown into doubt with the discovery of a large number of negative unpublished studies. ${ }^{26}$ In sum, the simplistic treatment response distinction between antidepressants for MDD and mood stabilizers/neuroleptics for bipolar disorder was greatly weakened.

\section{BIPOLAR SPECTRUM CONCEPTS}

About two decades after DSM-III, at the turn of the new millennium, many experts in bipolar illness began to move towards the bipolar spectrum concepts previously advanced by Akiskal and Koukopoulos. Different types of spectrum concepts were developed. Akiskal's approach emphasized subtyping: ${ }^{27}$ type II had been officially accepted in DSM-IV in 1994, allowing for mild manic episodes called hypomania, if they occurred with recurrent depression. Akiskal proposed adding type III, antidepressant induced hypomania, and other subtypes including depression with a family history of bipolar disorder, and mood temperaments, in particular hyperthymia, meaning constant hypomania as part of one's personality (not episodic episodes as in type II bipolar illness).

Koukopoulos emphasized mixed states: ${ }^{28}$ he defined "mixed depression" as depression occurring with excitation, meaning manic symptoms (like flight of ideas or talkativeness), but also agitation, irritability and rage, marked anxiety, and suicidal impulsivity. Koukopoulos saw this highly agitated and tense depressive state as the opposite of melancholia, which is markedly psychomotor retarded and not irritable or rageful. He thought that mixed depression gets much worse with antidepressants and responds to neuroleptics, while melancholia responds best to ECT and sometimes to antidepressants, but is best prevented with mood stabilizers like lithium. Other researchers, like Franco Benazzi in particular, studied mixed depression in detail and reported high rates in bipolar illness, but also notable rates in $\mathrm{MDD}^{29-33}$ Working with Akiskal, Benazzi replicated his Italian findings in other settings. ${ }^{34}$

Angst, whose work had been so central to the move away from Kraepelin's MDI, continued his Zurich study and found many intermediate forms of mood conditions between the original bipolar and unipolar ideal types. ${ }^{35,36} \mathrm{He}$ also described the presence of mixed states as very common in all depressive conditions. Defined as 3 or more manic symptoms occurring for any duration (not limited to four days or longer as in DSMIV), Angst and his colleagues have reported that about onehalf of all depressive episodes, even in MDD, involve mixed states with the presence of manic symptoms. ${ }^{37}$ Thus, Angst has become supportive of the bipolar spectrum concept. ${ }^{36,38}$

I have proposed an approach to the spectrum concept that focuses on how to distinguish it from unipolar depression. ${ }^{39}$ Taking into account all of the above work, instead of subtyping further, I suggested having a general definition for those patients who fall in the middle of the mood spectrum between the classic unipolar and type I bipolar extremes. This "bipolar spectrum disorder" would represent recurrent severe depression (as in Leonhard's unipolar depression), but with a family history of bipolar disorder or antidepressant-induced mania or a number of other features of bipolarity to depressive symptoms, course, or treatment response (mixed or melancholic features, early age of onset, many episodes, poor antidepressant response or tolerance). The presence of hyperthymic or cyclothymic mood temperaments was also suggested to be part of this bipolar spectrum concept. ${ }^{39}$ Defined this way, about one-third of MDD could be seen as meeting the bipolar spectrum definition. ${ }^{40,41}$

\section{THE PRIMACY OF MANIA}

A very original approach to the bipolar spectrum notion, advanced by Koukopoulos, ${ }^{42}$ is the primacy of mania hypothesis, the notion that depression cannot happen without ma- 
nia: mania is the fire, depression is the ash. This notion harkens back even beyond the bipolar spectrum concept to Kraepelin's original, much broader notion of manic-depressive illness. Koukopoulos has suggested that mania and depression always go together; the Leonhardian/DSM-III project of trying to separate them is thus misguided. We should not try to separate what is inseparable.

Koukopoulos defines mania broadly, as any form of excitation; this can represent DSM-III type mania criteria, but also psychomotor agitation, marked anxiety, and mood temperaments like hyperthymia or cyclothymia. Koukopoulos' hypothesis is that in almost all depressive presentations, there will be the co-occurrence or prior occurrence of mania, thus defined. Thus, often, depressive episodes follow manic episodes; or they occur after years of hyperthymic or cyclothymic temperament, or they represent mixed depression as defined above. Pure depression, without any of the above manic-like features, is relatively uncommon, according to this view. Since mania is the preceding or driving force to depression, on this notion, then the treatment of most depressive conditions would be anti-manic treatments, i.e., mood stabilizers or neuroleptics. Antidepressants are only mild symptomatic agents, improving symptoms superficially if at all. The best treatments for depression, in this perspective, would be, ironically, drugs we don't call antidepressants: the mood stabilizers or neuroleptics. Koukopoulos' approach only seems odd when we accept the post 1980 DSM-III mood dichotomy as self-evident. If we think about Kraepelin's prior unitary broad MDI concept instead, Koukopoulos' theory would be easier to understand, and would be quite consistent with Kraepelin's nosology.

\section{PERSONALITY “DISORDERS”}

Another category of illness that becomes discussed in relation to bipolar spectrum concepts is personality "disorders", in particular borderline personality. By using the term "disorder", which I put in quotes to emphasize that it is a vague concept with unclear meaning, proponents of DSM categories have equalized all diagnoses. ${ }^{9}$ This is a major conceptual error, an ontological mistake, which means a mistake in understanding the basic nature of different things. Red skies differ from red apples; they are very different things; they are similar only superficially by being red in color. Similarly, manic-depressive illness is a disease of the body and brain, with many well-known biological abnormalities that are well-replicated; it has been defined more or less as it is at least for a century or more; its definition is squarely in the medical model, requiring no beliefs beyond the acceptance of standard medical concepts like signs, symptoms, syndromes, course, genetics, and biology. Borderline personality, in contrast, is, in my view, our cul- ture's interpretation of what used to be called "hysteria". It is a Freudian interpretation of dissociative symptoms that happen in persons who experience trauma, usually sexual, early in life, in such a way that their personality development is derailed. ${ }^{43}$ It requires the ideological commitment to a host of psychoanalytic speculations, such as transference, countertransference, projection, denial, and so on. ${ }^{43}$ Its biology is poorly understood, and it is much less than genetic than manic-depressive illness. ${ }^{44,45}$ The concept, as now used, was invented about 40 years ago.

These two clinical constructs are entirely different in their histories and key characteristics. All they share in common is mood lability and impulsivity. Many other psychiatric pictures include impulsivity (gambling addiction, substance abuse) or mood lability (frontal lobe syndrome, agitation of multiple causes). These superficial symptoms are like the redness of skies versus apples. They are not core features of these conditions, which differ so markedly in other ways.

What is core to manic-depressive illness? Not mood lability. My view would be that psychomotor activation is central to manic-depressive illness, ${ }^{46}$ not mood per se. There is rapid thinking and feeling and movement, which sometimes can be related to impulsivity but often is not. In borderline personality, our modern version of hysteria, the key symptom feature is dissociation, which is related to the flashbacks and nightmares of that condition ${ }^{43}$ (which do not happen in MDI). ${ }^{47}$

Another way of trying to better distinguish these conditions is to look at non-symptom features that increase the prior probability of the condition, even before looking at specific manic or dissociative symptoms. This approach greatly increases true positive diagnoses, and decreases false positives. ${ }^{48}$ In bipolar illness, those diagnostic accuracy-enhancing features include a family history of bipolar illness and a severe episodic course with duration of episodes being weeks to months. ${ }^{48}$ In borderline personality, those diagnostic accuracy-enhancing features include childhood sexual abuse and repeated non-suicidal self-injury. ${ }^{43}$ These features are multiple times more frequent in borderline personality than in bipolar illness. ${ }^{49,50}$

The aspects of the bipolar spectrum that most raise the issue of differential diagnosis with borderline personality have to do with mood temperaments, like hyperthymia and cyclothymia. ${ }^{51}$ Since those conditions are chronic, not episodic, the course distinction of severe episodic recurrence is not helpful in distinguishing those mood temperaments from borderline personality. However, all the other distinguishing features still apply: a bipolar family history in favor of mood temperaments, and childhood sexual abuse and repeated non-suicidal self-injury in favor of borderline personality.

It is well to give up the term "disorder" and remind ourselves that superficial similarities are few, and major differences are 
many, when examining these conditions. Kraepelin distinguished between "disease-processes" (krankheitsprozessen), like MDI, and "clinical pictures", ${ }^{2,53}$ like the whole range of anxious, mood, and dissociative symptom presentations that are seen in hysteria. The bipolar spectrum is a disease-process; borderline personality is a clinical picture, but not a disease. They differ in kind, although they have superficial symptom similarities. Neither is part of the other, or should be confused with the other.

Red skies are not red apples.

\section{ANTIDEPRESSANT OUTCOMES}

A key practical relevance to bipolar spectrum concepts is that it helps identify those patients who do not do well with antidepressants, and who should not receive them, and those who do well with mood stabilizers and/or neuroleptics. The various bipolar spectrum concepts above predict that such patients will have more non-response to full therapeutic trials of antidepressants. ${ }^{39}$ They get labeled "treatment-resistant depression", which is misleading since their depression is not resistant to treatment at all, if they receive the correct treatments (mood stabilizers and/or neuroleptics). Besides not responding, bipolar spectrum patients are more likely to experience antidepressant-induced mania, and long-term rapid-cycling caused by antidepressants, with a worsening course of illness over time. ${ }^{39,54}$ Sometimes, antidepressant-induced worsening involves mixed episodes, ${ }^{28}$ which some experts believe may be part of the reason why some patients commit suicide in association with antidepressant use. ${ }^{55}$ In my own clinical experience, I would agree with this assessment, especially when antidepressants are given to patients with mixed depression, as defined by Koukopoulos. ${ }^{28}$ Not paying attention to the bipolar spectrum can be fatal for patients who receive antidepressants.

Further, if these patients are misconceived as having personality "disorders", long-term psychotherapies as the primary intervention will also be fruitless.

Since so much of the psychiatric establishment has opposed spectrum concepts consistently for the past three decades, there is very little research on exactly which treatments are most effective among the neuroleptics and mood stabilizers, at which doses, and for how long. Some limited research on cyclothymia with valproate suggested effectiveness with low levels, in the 30 s range ${ }^{56}$ but that evidence has not been replicated or extended to other mood stabilizers.

\section{THE BIPOLAR SPECTRUM IN A POST-DSM-IV WORLD}

The International Society for Bipolar Disorders (ISBD) con- vened a task force of experts which, using the available scientific evidence, recommended that a bipolar spectrum disorder definition be included in future psychiatric nosologies. DSM5 did not even seriously consider this idea. ${ }^{57}$

There has been a great deal of controversy in the last few years leading up to the publication of DSM-5 in 2013. Unfortunately, in relation to mood illnesses, it is clear that the fundamental error of 1980 in defining major depressive disorder extremely broadly will not be fixed. This MDD definition has become immortal in psychiatry, untouchable by data. As described above, Angst, who had helped formulate the concept in the 1970s based on his Zurich study up to that date, has provided 30 more years of follow-up in the same Zurich study, which argues for the bipolar spectrum concept and against the current MDD concept. Yet even though his work was part of the basis for the MDD concept in 1980, DSM- 5 nosologists refused to accept his work 30 years later to revise the MDD concept. $^{58}$

This illogicality is driven by something other than science, and this has become clear by the fact that three decades of biological research has failed to identify genes, or pathophysiology, or pharmacological treatment using DSM-III and IV categories. Recently, the National Institute of Mental Health (NI$\mathrm{MH}$ ) leadership has admitted clearly what psychiatric leaders had not admitted in the past: DSM categories are mostly unscientific and should not be the basis for scientific research. ${ }^{59}$ The bipolar spectrum concept has been excluded from DSM categories because of a wish to maintain narrow psychiatric diagnostic definitions to avoid overdiagnosis. We have shown that this approach is doomed to fail, because, for low prevalence illnesses like bipolar illness, diagnostic specificities of over $95 \%$ would be needed to achieve lower than $50 \%$ false positive overdiagnosis rates. ${ }^{48}$ The solution instead is to increase prior probabilities by assessing risk factors that are strongly associated with a diagnosis, like family history of bipolar disorder and episodic course and early age of onset. ${ }^{39,48}$

For the past two generations, world psychiatry has been confined by DSM categories, with the belief that those categories were reliable (which they often are) and would be increasingly valid. They clearly have failed the validity criterion, and it is likely, one hopes, that future psychiatry will put aside the pretensions of DSM definitions, and turn to honest study of psychiatric syndromes without the refusal to accept concepts based on non-scientific grounds, as is commonly the case with DSM revisions. The NIMH Research Domains Criteria $(\mathrm{RDoC})$ approach opens the way towards a scientific psychiatric nosology. ${ }^{60}$ Basing clinical criteria on clinical research only would be another way to progress, complementary to the RDoC approach. The ISBD diagnostic task force recommendations can form the basis of proposed new 21st century 
Research Diagnostic Criteria (RDC-21), including a definition of bipolar spectrum disorder. These new RDC-21 are being developed presently.

One can hope that future research will be conducted with these bipolar spectrum definitions, further validating or invalidating them, and provide better data for future clinicians to be able to use these concepts, if validated, for better clinical outcomes.

\section{REFERENCES}

1. Kraepelin E. Manic-Depressive Insanity and Paranoia. Edinburgh: E \& S Livingstone; 1921.

2. Goodwin F, Jamison K. Manic Depressive Illness, 2nd Edition. New York: Oxford University Press; 2007.

3. Leonhard K. The Classification of Endogenous Psychoses. New York: Irvington; 1957.

4. Woodruff RA, Goodwin DW, Guze SB. Psychiatric Diagnosis, First Edition. New York: Oxford University Press; 1974.

5. Spitzer RL, Endicott J, Robins E. Research diagnostic criteria: rationale and reliability. Arch Gen Psychiatry 1978;35:773-782.

6. Association AP. Diagnostic and Statistical Manual of Mental Disorders, Third Edition. Washington, DC: American Psychiatric Association; 1980.

7. Shorter E. Before Prozac: The Troubled History of Mood Disorders in Psychiatry. New York: Oxford University Press; 2009.

8. Roth S, Kerr T. The Concept of Neurotic Depression: A Plea for Reinstatement. In: Pichot P, Rein W, Editors. The Clinical Approach in Psychiatry. Paris, France: Synthelabo, 1994, p.339-368.

9. Ghaemi SN. Taking Disease Seriously: Against "Pragmatic" Nosology. In: Kendler KS, Parnas J, Editors., Philosophical Issues in Psychiatry II: Nosology. Oxford: Oxford University Press, 2012, p.42-52.

10. Perris C. A study of bipolar (manic-depressive) and unipolar recurrent depressive psychoses. Acta Psychiatrica Scandinavica Suppl 1966;194: 9-14.

11. Klerman G. Historical Perspectives on Contemporary Schools of Psychopathology. In: Theodore Millon, Editor. Contemporary Directions in Psychopathology: Toward the DSM-IV. New York: Guilford Press, 1986, p.3-28.

12. Ghaemi SN. On Depression: Diagnosis, Drugs, and Despair in the Modern World. Baltimore: Johns Hopkins University Press; 2013.

13. Robins E, Guze SB. Establishment of diagnostic validity in psychiatric illness: its application to schizophrenia. Am J Psychiatry 1970;126:983987.

14. Angst J. On the etiology and nosology of endogenous depressive psychoses. A genetic, sociologic, and clinical study. Monogr Gesamtgeb Neurol Psychiatr 1966;112:1-118.

15. Schildkraut JJ. The catecholamine hypothesis of affective disorders: a review of supporting evidence. Am J Psychiatry 1965;122:509-522.

16. Akiskal HS. The Bipolar Spectrum: New Concepts in Classification and Diagnosis. In: Grinspoon L, Editor. Psychiatry Update; The American Psychiatric Association Annual Review, Vol. 2. Washington DC: American Psychiatric Press; 1983, p.271-292.

17. Koukopulos A, Reginaldi P, Laddomada G, Floris G, Serra G, Tondo L. Course of the manic-depressive cycle and changes caused by treatment. Pharmakopsychiatr Neuropsychopharmakol 1980;13:156-167.

18. Koukopoulos A, Tundo A. A mixed depressive syndrome. Clin Neuropharmacol 1992;15(Suppl 1)Pt A:626A-627A.

19. Gershon ES, Hamovit J, Guroff JJ, Dibble E, Leckman JF, Sceery W, et al. A family study of schizoaffective, bipolar I, bipolar II, unipolar and normal control probands. Arch Gen Psychiatry 1982;39:1157-1167.

20. Prien RF, Klett CJ, Caffey EM Jr. Lithium prophylaxis in recurrent af- fective illness. Am J Psychiatry 1974;131:198-203.

21. Hyman SE, Nestler EJ. Initiation and adaptation: a paradigm for understanding psychotropic drug action. Am J Psychiatry 1996;153:151-162.

22. Manji HK. G proteins: implications for psychiatry. Am J Psychiatry 1992;149:746-760.

23. Manji HK, Moore GJ, Rajkowska G, Chen G. Neuroplasticity and cellular resilience in mood disorders. Mol Psychiatry 2000;5:578-593.

24. Nelson JC, Papakostas GI. Atypical antipsychotic augmentation in major depressive disorder: a meta-analysis of placebo-controlled randomized trials. Am J Psychiatry 2009;166:980-991.

25. Goodwin GM, Bowden CL, Calabrese JR, Grunze H, Kasper S, White R, et al. A pooled analysis of 2 placebo-controlled 18-month trials of lamotrigine and lithium maintenance in bipolar I disorder. J Clin Psychiatry 2004;65:432-441.

26. Turner EH, Matthews AM, Linardatos E, Tell RA, Rosenthal R. Selective publication of antidepressant trials and its influence on apparent efficacy. N Engl J Med 2008;358:252-260.

27. Akiskal HS, Pinto O. The evolving bipolar spectrum. Prototypes I, II, III, and IV. Psychiatr Clin North Am 1999;22:517-534.

28. Koukopoulos A, Sani G, Koukopoulos AE, Manfredi G, Pacchiarotti I, Girardi P. Melancholia agitata and mixed depression. Acta Psychiatr Scand Suppl 2007;(433):50-57.

29. Benazzi F. Depressive mixed states: unipolar and bipolar II. Eur Arch Psychiatry Clin Neurosci 2000;250:249-253.

30. Benazzi F. Depressive mixed state: testing different definitions. Psychiatry Clin Neurosci 2001;55:647-652.

31. Benazzi F. Depressive mixed state frequency: age/gender effects. Psychiatry Clin Neurosci 2002;56:537-543.

32. Benazzi F. Mixed depression: a clinical marker of bipolar-II disorder. Prog Neuropsychopharmacol Biol Psychiatry 2005;29:267-274.

33. Benazzi F. Mixed depression and the dimensional view of mood disorders. Psychopathology 2007;40:431-439.

34. Benazzi F, Akiskal HS. Delineating bipolar II mixed states in the Ravenna-San Diego collaborative study: the relative prevalence and diagnostic significance of hypomanic features during major depressive episodes. J Affect Disord 2001;67:115-122.

35. Angst J. The emerging epidemiology of hypomania and bipolar II disorder. J Affect Disord 1998;50:143-151.

36. Angst J. The bipolar spectrum. Br J Psychiatry 2007;190:189-191.

37. Angst J, Azorin JM, Bowden CL, Perugi G, Vieta E, Gamma A, et al. Prevalence and characteristics of undiagnosed bipolar disorders in patients with a major depressive episode: the BRIDGE Study. Arch Gen Psychiatry 2011;68:791-798.

38. Angst J, Gamma A, Bowden CL, Azorin JM, Perugi G, Vieta E, et al. Diagnostic criteria for bipolarity based on an international sample of 5,635 patients with DSM-IV major depressive episodes. Eur Arch Psychiatry Clin Neurosci 2012;262:3-11.

39. Ghaemi SN, Ko JY, Goodwin FK. "Cade's disease" and beyond: misdiagnosis, antidepressant use, and a proposed definition for bipolar spectrum disorder. Can J Psychiatry 2002;47:125-134.

40. Smith DJ, Harrison N, Muir W, Blackwood DH. The high prevalence of bipolar spectrum disorders in young adults with recurrent depression: toward an innovative diagnostic framework. J Affect Disord 2005;84: 167-178.

41. Rybakowski JK, Suwalska A, Lojko D, Rymaszewska J, Kiejna A. Types of depression more frequent in bipolar than in unipolar affective illness: results of the Polish DEP-BI study. Psychopathology 2007;40:153-158.

42. Koukopoulos A, Ghaemi SN. The primacy of mania: a reconsideration of mood disorders. Eur Psychiatry 2009;24:125-134.

43. Gunderson J. Borderline Personality Disorder. Washington DC: American Psychiatric Press; 1984.

44. Kendler KS, Prescott C. Genes, Environment, and Psychopathology. New York: Guilford Press; 2006.

45. Bienvenu OJ, Davydow DS, Kendler KS. Psychiatric 'diseases' versus behavioral disorders and degree of genetic influence. Psychol Med 2011; 


$$
\text { 41:33-40. }
$$

46. Cassano GB, Rucci P, Benvenuti A, Miniati M, Calugi S, Maggi L, et al. The role of psychomotor activation in discriminating unipolar from bipolar disorders: a classification-tree analysis. J Clin Psychiatry 2012;73: 22-28.

47. Benazzi F. Borderline personality-bipolar spectrum relationship. Prog Neuropsychopharmacol Biol Psychiatry 2006;30:68-74.

48. Phelps J, Ghaemi SN. The mistaken claim of bipolar 'overdiagnosis': solving the false positives problem for DSM-5/ICD-11. Acta Psychiatr Scand 2012;126:395-401.

49. Zanarini MC. Childhood experiences associated with the development of borderline personality disorder. Psychiatr Clin North Am 2000;23: 89-101.

50. Nock MK, Kessler RC. Prevalence of and risk factors for suicide attempts versus suicide gestures: analysis of the National Comorbidity Survey. J Abnorm Psychol 2006;115:616-623.

51. Akiskal HS. Demystifying borderline personality: critique of the concept and unorthodox reflections on its natural kinship with the bipolar spectrum. Acta Psychiatr Scand 2004;110:401-407.

52. Beumont PJ. Phenomenology and the history of psychiatry. Aust N Z J Psychiatry 1992;26:532-545.

53. Decker HS. The psychiatric works of Emil Kraepelin: a many-faceted story of modern medicine. J Hist Neurosci 2004;13:248-276.

54. Ghaemi SN, Hsu DJ, Soldani F, Goodwin FK. Antidepressants in bipolar disorder: the case for caution. Bipolar Disord 2003;5:421-433.

55. Berk M, Dodd S. Are treatment emergent suicidality and decreased response to antidepressants in younger patients due to bipolar disorder being misdiagnosed as unipolar depression? Med Hypotheses 2005;65: 39-43.

56. Jacobsen FM. Low-dose valproate: a new treatment for cyclothymia, mild rapid cycling disorders, and premenstrual syndrome. J Clin Psychiatry 1993;54:229-234.

57. Ghaemi SN, Bauer M, Cassidy F, Malhi GS, Mitchell P, Phelps J, et al. Diagnostic guidelines for bipolar disorder: a summary of the International Society for Bipolar Disorders Diagnostic Guidelines Task Force Report. Bipolar Disord 2008;10:117-128.

58. Association AP. Diagnostic and Statistical Manual of Mental Disorders, Fifth Edition. Washington, DC: American Psychiatric Association; 2013.

59. Cuthbert BN, Insel TR. Toward the future of psychiatric diagnosis: the seven pillars of RDoC. BMC Med 2013;11:126.

60. Insel T, Cuthbert B, Garvey M, Heinssen R, Pine DS, Quinn K, et al. Research domain criteria (RDoC): toward a new classification framework for research on mental disorders. Am J Psychiatry 2010;167:748-751. 